\title{
Socio-Economic Status and Life Expectancy in Lebanon: An Empirical Analysis
}

\author{
Marc Audi, Ph.D \\ University Paris 1 Pantheon Sorbonne/Azm University \\ Amjad Ali, Ph.D \\ University of the Punjab, Lahore. Pakistan
}

\begin{abstract}
This study has investigated the impact of socio-economic status on life expectancy in the case of Lebanon over the period of 1971 to 2014. Availability of food, CO2 emissions, secondary school enrollment, per capita income and population growth are used for reviewing socio-economic status of Lebanon. Johansen test is used for examining co-integration among variables. The results of Johansen co-integration show that there is co-integration among the variables of the model. The long run results of the model show that all selected independent variables of the model have significant impact on life expectancy in Lebanon. The causality test results reveal that all the independent variables have causal relationship with life expectancy at birth in the Lebanese case over the selected time period. The estimated results suggest that if government of Lebanon wants to increase life expectancy at birth, it has to improve its socio-economic status of its masses.
\end{abstract}

\section{INTRODUCTION}

At the end of the $20^{\text {th }}$ century, life expectancy at birth got much importance as an indicator of socio-economic development both in developed and developing world. The empirics reveal that much investment in education, health, environment protection, social safety nets and sanitation changed the living standards at world level (UN Development Program, 1997). Rising level of income per capita has started to change the expenditure of developing countries. Now most of the developing countries have good sanitation, literacy rate, nutrition, clean drinking water and decreasing poverty rate which are necessary for long life. But still, there is large number of under-developed countries in Africa where life expectancy has decreasing trends although income per capita and health expenditures are improved as in the case of Sierra Leone where the average life expectancy is 37 year (World Bank, 1997).

Generally, life expectancy is considered a topic of demographic studies but studies of Preston (1975, 1976, 1980), Grosse and Aufiey (1989) and Kakwani (1993) have considered it an important part of development economics. Now there are number of studies that are available which investigate the impact of socio-economic and political factors on life expectancy (Shen and Williamson, 1997; Mahfuz, 2008; Lake and Baum, 2001; Franco et al., 2004; Gerring et al., 2005; Navarro et al., 2006 and Ali and Khalil, 2014. Cumper (1984) and Wolfe (1986) but on the other hand, Poikolainen and Eskola (1988) and Hertz et al., (1994) mention that medical services play an important role in the determination of health status. Lake and Baum (2001) and Navarro et al., (2006) point out that public health expenditures and medical care improve quality of life. Moser et al., (2005) and Vagero (2007) mention that life expectancy show the pattern of growth over the long span of time but variability exist among the world's countries. Normally life expectancy is used for over viewing the living standard and human well-being of a nation, as it is attached with socio-economic development (Lomborg, 2002). From the last few decades, life expectancy has a rising trend in the world and this rise is specifically 
witnessed in developed countries. On one side increasing life expectancy is attached with preventative as well as maternal care, better working and living environments, increasing education and per capita income. On the other side, life expectancy provides detail information about environmental quality and health measures of a nation.

Socio-economic changes have very strong impact on life expectancy as depressing per capita income depresses purchasing power of households and it further decrease life expectancy in the long run. As a biological need for human beings, availability of food is essential for human life's span. Forbes and McGregor (1984) mentioned that the relationship between economic growth and mortality rate is very controversial. The results of this study reveal that unemployment being the leading macroeconomic variable, has positive impact on mortality rate in Scotland. This means that rising macroeconomic instability reduces life expectancy.

There are number of policy issues regarding life expectancy which impact fertility, intergenerational transfers, economic growth, social security and human capital investment. One of the main objectives of welfare state is to provide healthy environment, required food to it masses with stable macroeconomic conditions, so the study of life expectancy is very important for governments and policy makers. Since its independence, Lebanon has gone through a number of demographic, social and economic changes. Normally, most of the available policies in previous literature are based on panel or cross country studies. This study is country specific and the target is Lebanon and the examination of the impact of availability of food, $\mathrm{CO} 2$ emissions, secondary school enrollment, per capita income and population growth on life expectancy in that country. This type of empirical exercise is hardly done in the case of Lebanon. This study will be a healthy contribution in respective literature and helpful for improving life expectancy and its policy framework.

\section{LITERATURE REVIEW}

Grossman (1972) examines the relationship of health and inflation. The results of the study reveal that there is negative relationship between life expectancy and inflation. Moreover, the study concludes that increasing inflation rate put reverse impact on household welfare. Rogers (1979) discusses the relationship between life expectancy and unequal income distribution. The author presents the first conceptual framework for level of income and human mortality rate. Collins and Klein (1980) and Elola et al., (1995) investigate the determinants of health status in case of European countries. These studies conclude that primary health spending has positive and significant impact on health status in Europe. Rogers and Wofford (1989) and Mehfuz (2008) examine the major determinants of life expectancy selected developing countries. The study concludes that level of education, clean drinking water, urbanization, agricultural population, doctors per thousand population and calories intake determine life expectancy in case of developing countries. Davies and Kuhn (1991) describes that availability of food determines the health outcomes. Social security benefits and investment in health sectors reverse the morality rate. Ehrlich and Lui (1991) mention that life expectancy has positive relationship with investment in education. Hitiris and Posnet (1992) and World Bank (1997) mention that health care's spending and per capita income play an important role in deciding life expectancy. Rogot et al., (1992) mention that family income, level of education and employment status of household are main determinants of life expectancy in US. Barro and Sala-i-Martin (1995) explore the relationship between life expectancy and economic growth. The results of the study conclude the positive and significant relationship between economic growth and life expectancy. William and Boehmer (1997) investigate the determinants of female life expectancy. The study reveals that health cares expenditures, gender stratification 
and economic development enhance female life expectancy. Zhang et al. (2001) point out that there is inverse relationship between mortality rate and economic growth.

Guralnik et al. (1993) examine the life expectancy difference between white and black communities in the US. The results of the study show that white community has higher life expectancy compared to the black community in US. Nevertheless, increasing level of education converges the life expectancy of black community towards white community. Moreover, public health spending increases the overall life expectancy in US. Anand and Ravallion (1993) explore the relationship among per capita income, health expenditures and life expectancy. They conclude that health expenditures and per capita income have positive and significant relationship with life expectancy. Hill and King (1995) and Gulis (2000) examine the relationship between average years of schooling and health status. The results of these studies revealed that education especially literacy rate of female have positive relationship with life expectancy. Wilkinson (1996) points out that when a country achieved the threshold level of per capita income, the relationship between per capita income and standard of living becomes ambiguous. The study further mentions that increasing per capita income is not necessarily increase life expectancy but there is positive and significant relationship between per capita income and life expectancy.

Sen (1999) examines the determinants of life expectancy in case of Indian State Kerala. The study explores that education affect health status both directly and indirectly. Sen (1999) mention that higher education improves productivity of labor and improved labor productivity has increasing relationship with child's health. Hence education indirectly improves the health status. The findings of this study reveal that education is positively related to life expectancy of female. Cemieux et al., (1999) investigate the relationship of health status and health spending in Canada. The results of the study show that health spending has direct positive and significant relationship health status in Canada.

Kalediene and Petrauskiene (2000) investigate the socio-economic determinants of life expectancy. The results reveal that there is positive and significant relationship between urbanization and life expectancy, the study mentions that urban people are attached with better education and health cares. The study concludes that socio-economic factors have both direct and indirect relationship with life expectancy. Macfarlane et al. (2000) examine the health staus of some selected countries of Africa and Asia. The study shows that availability of food and access to safe drinking water has significant impact on life expectancy both in Asia and Africa. Veugelers et al. (2001) examine the determinants of life expectancy in Canada. For empirical analysis, they use multi-logistic regression analysis. The results of the study reveal that socio-economic factors have deep rooted impact on life expectancy in Canada. Hussain (2002) examine the determinants of life expectancy in 91 developing countries. Fertility rate, per capita calories and adult literacy rate are taken as independent variables and multiple OLS regression analysis is used for empirical estimations. The results of the study reveal that selected variables have deep rooted impact on life expectancy in case of all selected developing countries. Hence for improving the living standard, the developing countries must provide the basic necessities to its massive population.

Ali and Khalil (2014) investigate the impact of food production, school enrollment, inflation, population growth, per capita income and CO2 emissions on life expectancy for Sultanate of Oman. The estimated results reveal that food production and school enrollment has positive and significant relationship with life expectancy for Sultanate of Oman. On the other hand inflation and per capita income has negative but insignificant relationship with life expectancy for the Sultanate of Oman. The results show population growth has negative and significant 
relationship with life expectancy of Sultanate of Oman. In the long run $\mathrm{CO} 2$ emissions has positive and insignificant relationship with life expectancy but in the short run, it has negative and significant relationship with life expectancy. The findings suggest that government of Sultanate of Oman should seriously check these socio-economic factors for increasing life expectancy.

Ali and Audi (2016) investigate the impact of income inequality, globalization and environmental degradation on life expectancy in Pakistan over period 1980-2015. The results of the study reveal that income inequality and environmental degradation have negative and significant impact on life expectancy in Pakistan. On the other hand globalization has positive and significant impact on life expectancy in Pakistan. The results of Granger causality show that there is unidirectional causality running from all independent variables to dependent variable.

\section{THEORETICAL MODEL AND DATA SOURCES}

The objective of this study is to explore the impact of availability of food, CO2 emissions, secondary school enrollment, per capita income and population growth on life expectancy in Lebanon over the period of 1971 to 2014. Data for all the variables is taken from World Development Indicators (WDI) maintained by World Bank. Following the theoretical framework of Grossman (1972), Fayissa and Gutema (2005), Ali and Khalil (2014) and Ali and Audi (2016) the function form of study become as:

$$
\text { LIFE=f(FOOD, CO2, SSE, GDPP, POPG) }
$$

Where

LIFE= life expectancy at birth

FOOD=availability of food (food index)

$\mathrm{CO} 2=\mathrm{CO} 2$ emissions

SSE $=$ education standard (secondary school enrollment)

$\mathrm{GDPP}=$ per capita income

$\mathrm{POPG}=$ population growth

The econometric functional form of the model become as:

$$
\text { LIFEt }=+{ }_{1} \mathrm{FOODt}+{ }_{2} \mathrm{CO} 2 t+{ }_{3} \mathrm{SSE} t+{ }_{4} \mathrm{GDPPt}+{ }_{5} \mathrm{POPGt}+{ }_{t}
$$

\footnotetext{
Where

$\mathrm{T}=$ time period

= stochastic error term
}

\section{ECONOMETRIC METHODOLOGY}

Time series is indulged with unit root problem and unit root problem make the error of time series nonstationary. Augmented Dickey-Fuller (1981) is used for examining the stationarity of the variables of the model. Johansen (1988) proposed Johansen Co-integration test and Johansen and Juselius (1990) extended it for finding long run relationship of the variables when they are stationary at some order of integration. Originally, the co-integration concept was developed by Engle and Granger (1987). Engle and Granger (1987) proposed a two steps estimation for only one co-integrating vector, but Johansen (1988) and Johansen and Juselius (1990) proposed maximum likelihood test for finding the number of co-integrating vectors in demonstration of Vector Autoregressive (VAR). The common method of VAR is as below: 


$$
X_{t}={ }_{0}+{ }_{t} X_{t}{ }_{1}+\ldots \ldots+{ }_{k} X_{t}{ }_{k}+{ }_{t}
$$

Where $X_{t}$ is a $(\boldsymbol{n} \cdot \mathbf{1}) \quad$ vector of variables that are integrated at same order, ${ }_{0}$ is a $(n \cdot 1)$ vector of constant terms, ${ }_{t} \cdots e_{t}{ }_{k}$ are parameters and ${ }^{t}$ is the residual term, for Vector Error Correction Model (VECM) the VAR can be written in following form.

$$
X_{t}=+{ }_{i=0}^{1} i_{i} X_{t}+X_{t 1}+{ }_{t}
$$

Where $\boldsymbol{X}_{\boldsymbol{t}}$ is a $(\boldsymbol{n} \cdot \mathbf{1})$ column vector of variables, $\boldsymbol{u}$ is a $(\boldsymbol{n} \cdot \mathbf{1})$ vector of constant terms, $t$ is $(\boldsymbol{n} \cdot \mathbf{1})$ vector of usual error term, $\Delta$ is difference operator and as well as represent coefficient matrices. The coefficient matrix is representing the long run equilibrium relationship for the matrix. In this analysis two types of likelihood ratio tests are utilized (trace test statistics and maximum eigenvalue test statistics) for finding cointegrating vectors. VAR Granger Causality/Block Exogeneity Wald test is used for finding causal relationship among variables. This is going to test the causal relationship among life expectancy, availability of food, CO2 emissions, secondary school enrollment, per capita income and population growth.

\section{EMPIRICAL RESULTS AND DISCUSSION}

Augmented Dickey-Fuller unit root test results are presented in table-1. The results of ADF test show that life expectancy at birth, availability of food, CO2 emissions, secondary school enrollment, GDP per capita and population growth are not stationary at level. But all the selected variables of the model are stationary at first difference. So having the same order of integration among the variables of the model, the best method of co-integration is Johansen cointegration.

Table 1: Augmented Dickey-Fuller (ADF) Test for Unit Root

\begin{tabular}{|l|c|c|}
\hline \multicolumn{3}{|c|}{ Augmented Dickey-Fuller (ADF) Test at Level } \\
\hline \multicolumn{1}{|c|}{ Variables } & t -Statistic & p- Value \\
\hline LIFE & 0.717956 & 0.9910 \\
\hline FOOD & -1.315286 & 0.6140 \\
\hline CO2 & -0.991389 & 0.7480 \\
\hline SSE & 1.970863 & 0.2981 \\
\hline GDPP & 0.049335 & 0.9577 \\
\hline POPG & -1.091098 & 0.1349 \\
\hline \multicolumn{2}{|c|}{ Augmented Dickey-Fuller (ADF) Test at 1 1 Difference } \\
\hline Variables & t -Statistic & p-Value \\
\hline LIFE & -2.669221 & 0.0887 \\
\hline FOOD & 6.995631 & 0.0000 \\
\hline CO2 & 5.846525 & 0.0000 \\
\hline SSE & -5.680238 & 0.0000 \\
\hline GDPP & -4.239947 & 0.0017 \\
\hline POPG & -3.877576 & 0.0048 \\
\hline
\end{tabular}

Table 2 presents the results of lag length criterions. Generally, sequential modified LR test statistic (LR), Final prediction error (FPE), Akaike information criterion (AIC), Schwarz information criterion (SC) and Hannan-Quinn information criterion (HQ) are used for this 
purpose. So following the above lag length criterions maximum 2 lag length is selected for long run empirical analysis.

Table 2: VAR Lag Order Selection Criteria

\begin{tabular}{|c|c|c|c|c|c|c|}
\hline \multicolumn{7}{|c|}{$\begin{array}{c}\text { Endogenous variables: LIFE FOOD SSE CO2 GDPP PPOGR } \\
\text { Sample: } 19712014 \\
\text { Included observations: } 42\end{array}$} \\
\hline Lag & LogL & LR & FPE & AIC & SC & HQ \\
\hline 0 & -1186.460 & NA & $1.85 \mathrm{e}+17$ & 56.78380 & 57.03204 & 56.87479 \\
\hline 1 & -833.2204 & 588.7324 & $5.17 \mathrm{e}+10$ & 41.67716 & 43.41483 & 42.31409 \\
\hline 2 & -726.0485 & $147.9994^{*}$ & $1.94 \mathrm{e}+09^{*}$ & $38.28802^{*}$ & $41.51512^{*}$ & $39.47088^{*}$ \\
\hline \multicolumn{7}{|c|}{ * indicates lag order selected by the criterion } \\
\hline \multicolumn{7}{|c|}{ LR: sequential modified LR test statistic (each test at 5\% level) } \\
FPE: Final prediction error \\
AIC: Akaike information criterion \\
SC: Schwarz information criterion \\
HQ: Hannan-Quinn information criterion
\end{tabular}

Table 3 presents the results of Johansen's co-integration test. Maximum Eigen statistics and Trace statistics are used for determining the co-integration among the variables of the model. This study has investigated the socio-economic status on life expectancy in Lebanon over the period of 1971 to 2014 . The estimated trace statistics is greater than the critical value till $\mathrm{R} \leq 2$ hence it rejects the null hypothesis of no co-integration. The results show that there is 2 cointegrating relationship among the variables of the model. In the case of Maximum Eigen test statistic, the value of Max-Eigen is greater than critical value till $\mathrm{R} \leq 1^{*}$. So Max-Eigen value also confirms the existence of one co-integrating relationship among the variables of the model. On the bases of Trace statistic and Max-Eigen statistic it is concluded that there is co-integration among the model's variables.

Table 3: Unrestricted Co-integration Rank Test (Trace)

\begin{tabular}{|c|c|c|c|c|}
\hline $\mathrm{H}_{0}$ & $\mathrm{H}_{1}$ & Trace Statistic & $\begin{array}{c}0.10 \text { Critical } \\
\text { Value }\end{array}$ & Prob. $^{\mathrm{a}}$ \\
\hline $\mathrm{R}=0^{*}$ & $\mathrm{R} \geq 1$ & 176.1770 & 95.75366 & 0.0000 \\
\hline $\mathrm{R} \leq 1^{*}$ & $\mathrm{R} \geq 2$ & 82.58159 & 69.81889 & 0.0034 \\
\hline $\mathrm{R} \leq 2^{*}$ & $\mathrm{R} \geq 3$ & 50.73500 & 47.85613 & 0.0262 \\
\hline $\mathrm{R} \leq 3$ & $\mathrm{R} \geq 4$ & 30.17108 & 29.79707 & 0.0453 \\
\hline $\mathrm{R} \leq 4$ & $\mathrm{R} \geq 5$ & 13.16475 & 15.49471 & 0.1089 \\
\hline
\end{tabular}

Unrestricted Co-integration Rank Test (Max-Eigen)

\begin{tabular}{|c|c|c|c|c|}
\hline $\mathrm{H}_{0}$ & $\mathrm{H}_{1}$ & $\begin{array}{c}\text { Max-Eigen } \\
\text { Statistic }\end{array}$ & $\begin{array}{c}0.10 \text { Critical } \\
\text { Value }\end{array}$ & Prob. ${ }^{a}$ \\
\hline $\mathrm{R}=0^{*}$ & $\mathrm{R} \geq 1$ & 93.59537 & 40.07757 & 0.0000 \\
\hline $\mathrm{R} \leq 1^{*}$ & $\mathrm{R} \geq 2$ & 33.84659 & 31.87687 & 0.0857 \\
\hline $\mathrm{R} \leq 2$ & $\mathrm{R} \geq 3$ & 20.56392 & 27.58434 & 0.3034 \\
\hline $\mathrm{R} \leq 3$ & $\mathrm{R} \geq 4$ & 17.00633 & 21.13162 & 0.1717 \\
\hline $\mathrm{R} \leq 4$ & $\mathrm{R} \geq 5$ & 13.10936 & 14.26460 & 0.0755 \\
\hline
\end{tabular}

The long run relationship model results are presented in table 4. The estimated results show that food availability has positive and significant relationship with life expectancy at birth in Lebanon. The results show that a $1 \%$ increase in availability of food increases life expectancy at 
birth $0.056465 \%$. These results support the results of Ali and Khalil (2014) and Ali and Audi (2016). The coefficient of CO2 emissions shows the negative and significant relationship with life expectancy at birth in case of Lebanon. A 1\% increase in $\mathrm{CO} 2$ emissions causes to decrease $1.072773 \%$ in life expectancy at birth. These results support the study of Ali and Audi (2016) but contradict to Ali and Ahmad (2016). There is positive and significant impact of secondary school enrollment on life expectancy in Lebanon. The results reveal that $1 \%$ increase in secondary school enrollment brings $2.38 \mathrm{E}-05 \%$ positive change in life expectancy at birth in case in Lebanon. These results favor Ali and Ahmad (2014) and Ali and Audi (2016) where these studies claim that level of education play an important role for life longevity. The results show that there is positive and significant relationship between GDP per capita and life expectancy in Lebanon and 1\% change increase in GDP per capita brings $0.001062 \%$ increase in life expectancy at birth. Population growth positively impacts life expectancy at birth and has significant effect in Lebanon. The life expectancy at birth increases $0.285793 \%$ with a $1 \%$ increase in population growth. Over the selected time period, the model's overall results in the long run shows that availability of food, $\mathrm{CO} 2$ emissions, secondary school enrollment, GDP per capita and population growth have significant relationship with life expectancy in Lebanon. The results of the model show that by improving socio-economic status in Lebanon life expectancy at birth is further enhanced.

Table 4: Long Run Relationship

\begin{tabular}{|l|c|c|c|}
\hline \multicolumn{4}{|c|}{ Dependent Variable: LIFE } \\
\hline Variable & Coefficient & t-Statistic & p-Value \\
\hline FOOD & 0.056465 & 4.837052 & 0.0000 \\
\hline CO2 & -1.072773 & -3.263978 & 0.0024 \\
\hline SSE & $2.38 \mathrm{E}-05$ & 4.3338 & 0.0169 \\
\hline GDPP & 0.001062 & 10.40936 & 0.0000 \\
\hline POPG & 0.285793 & 2.517440 & 0.0163 \\
\hline
\end{tabular}

The short run estimated results, have been shown in table 5. In the short run, availability of food has positive and significant effect on life expectancy at birth in Lebanon. CO2 emissions and population growth has negative and significant short run impact on life expectancy at birth in Lebanon. The results reveal that secondary school enrollment and per capita income has negative and insignificant impact on life expectancy at birth and this short run relationship is opposite to long run relationship. The overall results reveal that life expectancy at birth is a long run phenomenon in Lebanon rather than short run. The ECM value is negative and significant which is theoretically correct and shows speed of convergence from short run time period to long run time period. The estimated value of ECM show 0.0043 percent short run deviation is corrected in long run.

Table 5: Short Run Estimates

\begin{tabular}{|l|c|r|r|}
\hline \multicolumn{4}{|l|}{ Dependent Variable $=$ DLIFE } \\
\hline Variable & Coefficient & t-Statistic & p-Value \\
\hline DFOOD & 1.650084 & 31.98166 & 0.0000 \\
\hline DCO2 & -0.781526 & -18.21171 & 0.0000 \\
\hline DSSE & $4.52 \mathrm{E}-06$ & 0.051877 & 0.9590 \\
\hline DGDPP & -0.000112 & -1.041380 & 0.3069 \\
\hline DPOPG & $-1.47 \mathrm{E}-07$ & -4.292610 & 0.0002 \\
\hline ECT & -0.004396 & -7.140292 & 0.0000 \\
\hline & & & \\
\hline
\end{tabular}




\begin{tabular}{|lc|}
\hline R-squared 0.999671 & Mean dependent var 0.306534 \\
Adjusted R-squared 0.999513 & S.D. dependent var 0.121664 \\
S.E. of regression 0.002686 & Akaike info criterion -8.736501 \\
Sum squared resid 0.000195 & Schwarz criterion -8.151379 \\
Log likelihood 193.0983 & Hannan-Quinn criter. -8.523432 \\
F-statistic 6311.875 & Durbin-Watson stat 1.929715 \\
\hline
\end{tabular}

The estimated results of VAR Granger Causality/Block Exogeneity Wald Tests are presented in the table 6 . The results show that there is bidirectional causality running between life expectancy at birth and availability of food in Lebanon. There is unidirectional causality is running from CO2 emissions to life expectancy at birth in Lebanon over the selected time period. The results reveal that unidirectional causality is running from secondary school enrollment to life expectancy at birth in case of Lebanon. There exists bidirectional causality is running between per capita income and life expectancy at birth in Lebanon. There is no causal relationship between population growth and life expectancy at birth over the selected time period. There is a unidirectional causality running between availability of food and $\mathrm{CO} 2$ emissions. There is bidirectional causality is running between availability of food and per income in Lebanon. There is no causal relationship between secondary school enrollment and between population growth and availability of food in Lebanon over the selected time period. The results reveal a unidirectional causality between secondary school enrollment and CO2 emissions in Lebanon. The result show a bidirectional causality running between per capita and $\mathrm{CO} 2$ emissions and between population growth and $\mathrm{CO} 2$ emissions in Lebanon. There is no causal relationship among secondary school enrollment, per capita and population growth in case of Lebanon over the selected time period. These findings have proposed that the Lebanese government of Lebanon should improve socio-economic status for improving life expectancy at birth. 
Table 6: VAR Granger Causality/Block Exogeneity Wald Tests

\begin{tabular}{|c|c|c|c|}
\hline \multicolumn{4}{|c|}{ Sample: 19712014} \\
\hline \multicolumn{4}{|c|}{ Included observations: 42} \\
\hline \multicolumn{4}{|c|}{ Dependent variable: LIFE } \\
\hline Excluded & Chi-sq & Df & Prob. \\
\hline FOOD & 27.16451 & 2 & 0.0000 \\
\hline $\mathrm{CO} 2$ & 27.00663 & 2 & 0.0000 \\
\hline SSE & 9.062265 & 2 & 0.0108 \\
\hline GDPP & 10.89355 & 2 & 0.0043 \\
\hline PPOGR & 0.134806 & 2 & 0.9348 \\
\hline All & 141.9768 & 10 & 0.0000 \\
\hline \multicolumn{4}{|c|}{ Dependent variable: FOOD } \\
\hline Excluded & Chi-sq & Df & Prob. \\
\hline LIFE & 9.932106 & 2 & 0.0070 \\
\hline $\mathrm{CO} 2$ & 3.773871 & 2 & 0.1515 \\
\hline SSE & 1.294614 & 2 & 0.5235 \\
\hline GDPP & 11.65383 & 2 & 0.0029 \\
\hline PPOGR & 0.258808 & 2 & 0.8786 \\
\hline All & 16.33016 & 10 & 0.0906 \\
\hline \multicolumn{4}{|c|}{ Dependent variable: $\mathrm{CO2}$} \\
\hline Excluded & Chi-sq & Df & Prob. \\
\hline LIFE & 4.387384 & 2 & 0.1115 \\
\hline FOOD & 16.29946 & 2 & 0.0003 \\
\hline SSE & 10.15484 & 2 & 0.0062 \\
\hline GDPP & 8.182654 & 2 & 0.0167 \\
\hline PPOGR & 7.634916 & 2 & 0.0220 \\
\hline All & 42.45152 & 10 & 0.0000 \\
\hline \multicolumn{4}{|c|}{ Dependent variable: SSE } \\
\hline Excluded & Chi-sq & Df & Prob. \\
\hline LIFE & 3.263201 & 2 & 0.1956 \\
\hline FOOD & 1.790704 & 2 & 0.4085 \\
\hline $\mathrm{CO} 2$ & 2.229016 & 2 & 0.3281 \\
\hline GDPP & 0.042891 & 2 & 0.9788 \\
\hline PPOGR & 4.244763 & 2 & 0.1197 \\
\hline All & 21.72663 & 10 & 0.0166 \\
\hline \multicolumn{4}{|c|}{ Dependent variable: GDPP } \\
\hline Excluded & Chi-sq & Df & Prob. \\
\hline LIFE & 5.974904 & 2 & 0.0504 \\
\hline FOOD & 6.176976 & 2 & 0.0456 \\
\hline $\mathrm{CO2}$ & 9.606328 & 2 & 0.0082 \\
\hline SSE & 2.898693 & 2 & 0.2347 \\
\hline PPOGR & 2.928848 & 2 & 0.2312 \\
\hline All & 36.40698 & 10 & 0.0001 \\
\hline \multicolumn{4}{|c|}{ Dependent variable: PPOGR } \\
\hline Excluded & Chi-sq & Df & Prob. \\
\hline LIFE & 3.271608 & 2 & 0.1948 \\
\hline FOOD & 2.679808 & 2 & 0.2619 \\
\hline $\mathrm{CO} 2$ & 7.000563 & 2 & 0.0302 \\
\hline SSE & 0.948539 & 2 & 0.6223 \\
\hline GDPP & 0.158611 & 2 & 0.9238 \\
\hline All & 17.51806 & 10 & 0.0637 \\
\hline
\end{tabular}




\section{CONCLUSIONS AND POLICY SUGGESTIONS}

This study has examined the impact of socio-economic status on life expectancy in Lebanon over the period of 1971 to 2014. Life expectancy at birth is taken as dependent variable whereas for socio-economic status, availability of food, CO2 emissions, secondary school enrollment, per capita income and population growth are taken as independent variables. Augmented Dickey-Fuller unit root test is used for reviewing stationarity of variables of the model. Johansen co-integration is used for examining the co-integration among the variables of the model. VAR Granger Causality/Block Exogeneity Wald Tests are used for examining the causal relationship among the variables of the model. ADF unit root test results show that all the variables of the model are stationary at first difference. The results of Johansen cointegration show that there is co-integration among the variables of the model. The model's long run results of the model show that all selected independent variables of the model have significant impact on life expectancy in Lebanon. The causality test results reveal that all the independent variables over the selected time period have causal relationship with life expectancy at birth in Lebanon. The estimated results suggest that if the Lebanese government wants to increase life expectancy at birth, it has to improve the socio-economic status of its masses.

\section{References}

Ali, A., and Ahmad, K. (2014). The Impact of Socio-Economic Factors on Life Expectancy in Sultanate of Oman: An Empirical Analysis. Middle-East Journal of Scientific Research, 22(2), 218-224.

Ali, A. and Audi, A. (2016). The Impact of Income Inequality, Environmental Degradation and Globalization on Life Expectancy in Pakistan: An Empirical Analysis. International Journal of Economics and Empirical Research, 4(4), 182-193.

Anand, S and M Ravallion (1993). Human Development in Poor Countries: Onthe Role of Private Income and Public Services. Journal of Economic Perspectives, 7(1),133-150.

Barro, R. J., and Sala-i-Martin, X. (1995) Economic growth, New York. Crémieux, P, P Ouellette, and C Pilon (1999). Economics of Health Care Systems: Health care spending as determinants of health outcomes. Health Economics, 8(7), 627-639.

Collins, E and R Klein (1980). Equity and the NHS: Self-reported morbidity, access and primary care. British Medical Journal, 281, 1111-1115.

Cumper, G. E. (1984). Determinants of Health Levels in Developing Countries, New York, Wiley.

Davies, J. B., and Kuhn, P. J. (1991). A dynamic model of redistribution, inheritance, and inequality. Canadian Journal of Economics, 324-344.

Dickey, D. and W. Fuller (1981). Likelihood Ratio Statistics for Autoregressive Time Series with a Unit Root. Econometrica 49,1057-1072.

Engle, R. F., and Granger, C. W. (1987). Co-integration and error correction: representation, estimation, and testing. Econometrica: journal of the Econometric Society, 251-276.

Elola, J. Daponte, A. and V Navarro (1995). Health indicators and the organization of healthcare systems in Western Europe. American Journal of Public Health, 85, 1397-1401.

Ehrlich, I., and Lui, F. T. (1991). Intergenerational trade, longevity, and economic growth. Journal of Political Economy, 1029-1059.

Fayissa, B. and Gutema, P. (2005). Estimating a health production function for Sub-Saharan Africa (SSA). Applied Economics, 37, 155-164.

Forbes, J. F. and McGregor, A. (1984). Unemployment and mortality in post-war Scotland. Journal of Health Economics, 3, 239-257.

Franco, A. Alvarez-Dardet, C. and Ruiz, M. T. (2004). Effect of democracy on health: ecological study. BMJ 329, 1421-1423. 
Gerring, J. Bond, P. Barndt, W. T. and Moreno, C. (2005). Democracy and economic growth: a historical perspective. World Polit, 57, 323-364.

Grosse, R. N. and Auffrey, C. (1989). Literacy and Health Status in Developing Countries. Journal of Annual Review of Public Health, 10, 281-297.

Grossman, M. (1972). The demand for health: a theoretical and empirical investigation. NBER Books.

Guralnik, J. M. Land, K. C. Blazer, D. Fillenbaum, G. G. and Branch, L.G. (1993). Educational Status and Active Life Expectancy anong Older Blacks and Whites. The New England Journal of Medicine, 329, 110-116.

Gulis, G (2000). Life expectancy as an indicator of environmental health. European Journal of Epidemiology, 16, 161-165.

Hertz, E. Hebert, J. R. and Landon, J. (1994). Social and Environmental Factors and Life Expectancy, Infant Mortality, and Maternal Mortality Rates: Results of a Cross-National Comparison. Social Science and Medicine, 39, 105-114.

Hitiris, T. and Posnet, J. (1992). The determinants and effects of health expenditure in developed countries" Journal of Health Economics, 11, 173-181.

Hill, M. A. and King, E. M. (1995). Women's education and economic well-being. Feminist Economics, 1, 21-46.

Husain, A. R. (2002). Life Expectancy in Developing Countries: A Cross-Section Analysis. The Bangladesh Development Studies 28.

Johansen, S. (1988). Statistical analysis of cointegration vectors. Journal of economic dynamics and control, 12 , 231-254.

Johansen, S. and Juselius, K. (1990). Maximum likelihood estimation and inference on cointegration-with applications to the demand for money. Oxford Bulletin of Economics and statistics, 52, 169-210.

Kalediene, R. and Petrauskiene, J. (2000). Regional life expectancy patterns in Lithuania. European Journal of Public Health, 10, 101-104.

Kakwani, N. (1993). Performance in Living Standards: An International Comparison. Journal of Development Economics, 41, 307-336.

Lake, D. A. and Baum, M. A. (2001). The invisible hand of democracy: political control and the provision of public services. Comp Polit Stud, 34, 587-621.

Lomborg, B. (2002). How healthy is the world? BMJ: British Medical Journal, 325, 1461.

Macfarlane, S. Racelis, M. and MuliMusiime, F. (2000). Public health in developing countries. Lancet, 356, 841-846.

Moser, K. Shkolnikov, V. Leon, D. A. (2005). World mortality 1950-2000: divergence replacesconvergence from the late 1980s. Bull World Health Organ, 83, 202-209.

Mahfuz, K, (2008). Determinants of life expectancy in developing countries. J Dev Areas 41, 185-204.

Navarro, V. Muntaner, C. Borrell, C. Benach, J. Quiroga, A. Rodriguez-Sanz, M. Verges, N. and Pasarin, M. I. (2006). Politics and health outcomes. Lancet, 368, 1033-1037.

Poikolainen, K. and Eskola, J. (1988). Health Services Resources and Their Relation toMortality from Causes Amenable to Health Care: A Cross-National Study. International Journal of Epidemiology, 17, 86-89.

Preston, S. H. (1976). Mortality Patterns in National Populations. Academic Press, New York.

Preston, S. H. (1980). Causes and Consequences of Mortality Declines in Less Developed

Countries During the Twentieth Century. in Easterlin, R.A., ed., Population and Economic Change in Developing Countries, Chicago, University of Chicago Press.

Rogers, G. B. (1979). Income and inequality as determinants of mortality: an international crosssection analysis. Population Studies, 33, 343-351.

Rogers, R. G. and Wofford, S. (1989). Life expectancy in less developed countries: socioeconomic development or public health. Journal of Biosociological Science, 21, 245-252.

Rogot, E. Sorlie, P. D. and Johnson, N. J. (1992). Life expectancy by employment status, income, and education in the national Longitudinal Mortality Study. Public Health Reports, 107, 457-461.

Sen, A. (1999). Critical reflection. Health and development. Bulletin of the World Health Organization, 77.

Shen, C. E. Williamson, J. B. (1997). Child mortality, women's status, economic dependency, and state strength: a 
cross-national study of less developed countries. Soc Forces, 76, 667-694.

Vagero, D. (2007). Health inequalities across the globe demand new global policies. Scand J Public Health, 35, 113115.

Veugelers, P. J. Yip, A. M. and Gephart, A. (2001). Proximate and Contextual Socioeconomic Determinants of Mortality: Multilevel Approaches in a Setting with Universal Health Care Coverage. American Journal of Epidemiology, 154, 543-546.

Wilkinson, R. G. (1996). Unhealthy Societies: The Afflictions of Inequality. Routledge, London.

Williamson, J. B. and Boehmer, U. (1997). Female life expectancy, gender stratification, and level of economic development: a cross national study of less developed countries. Social Science and Medicine, 45, 305-317.

Wolfe, B. (1986). Health Status and Medical Expenditures: Is There a Link? Social Science and Medicine, 22, 993999.

World Bank. (1997). World Development Indicators 1997. Washington D.C.

Zhang, J. Zhang, J. and Lee, R. (2001). Mortality decline and long-run economic growth. Journal of Public Economics, 80, 485-507. 